\title{
Pemodelan Faktor-faktor yang Mempengaruhi Kinerja Karyawan PT. Djarum Unit Karangbener, Kudus-Jawa Tengah Menggunakan Structural Equation Modeling
}

\author{
Yongky Choirul Anam dan Agus Suharsono \\ Departemen Statistika, Fakultas Matematika, Komputasi, dan Sains Data, \\ Institut Teknologi Sepuluh Nopember (ITS) \\ e-mail: gmagussuharsono@gmail.com
}

\begin{abstract}
Abstrak-PT Djarum merupakan perusahaan penghasil rokok yang sudah sangat terkenal di Indonesia. Perusahaan memiliki beberapa brak produksi rokok jenis Sigaret Kretek Tangan (SKT), salah satunya yaitu di Unit Karangbener yang berada di Desa Karangbenar, Kudus-Jawa Tengah. Perusahaan selalu mewujudkan suasana lingkungan kerja agar karyawan selalu merasa senang dan nyaman sehingga dapat optimal dalam bekerja dan dapat menghasilkan produk yang berkualitas baik. Namun dalam menilai kinerja karyawan, perusahaan belum mengetahui indikator-indikator yang dapat digunakan sebagai alat ukur. Oleh karena itu, dilakukan penelitian faktor-faktor yang mempengaruhi kinerja karyawan dengan menggunakan pendekatan Structural Equation Modeling (SEM) dikarenakan variabel yang digunakan adalah variabel yang tidak terukur (laten). Beberapa faktor yang diduga mempengaruhi kinerja karyawan antara lain kemampuan diri, motivasi, dan dukungan yang diterima. Data yang digunakan merupakan data primer dengan melakukan survey secara langsung kepada karyawan giling dan karyawan batil. Hasil penelitian menunjukkan bahwa kemampuan diri dan motivasi berpengaruh langsung terhadap kinerja karyawan, serta terdapat pengaruh tidak langsung dari dukungan sosial terhadap kinerja karyawan melalui motivasi.
\end{abstract}

Kata Kunci-Dukungan Sosial, Kemampuan Diri, Kinerja, Motivasi, Stuctural Equation Modeling.

\section{PENDAHULUAN}

CUATU perusahaan rokok yang sudah sangat terkenal di Indonesia yaitu PT Djarum menghasilkan 3 jenis produk rokok antara lain Sigaret Kretek Tangan (SKT), Sigaret Kretek Mesin (SKM) dan Sigaret Putih Mesin. PT Djarum mempunyai beberapa unit (brak) produksi, salah satunya adalah Unit Karangbener yang berada di Desa Karangbenar, Kudus-Jawa Tengah yang memproduksi rokok jenis Sigaret Kretek Tangan (SKT) yang dilakukan secara manual oleh tenaga kerja borongan terampil. Perusahaan ini menghasilkan produk-produk yang berkualitas tinggi secara konsisten dan inovatif untuk memuaskan konsumen, menciptakan citra positif yang kuat untuk perusahaan dan produk-produk yang dihasilkan, menciptakan manajemen profesional yang berdedikasi serta sumber daya manusia (SDM) yang kompeten. Dalam menciptakan SDM yang kompeten, terdapat Human Resources Development Department (HRD) Employee Development yang bertugas mengembangkan dan meningkatkan kualitas karyawan. Perusahaan selalu menerapkan kebijakan untuk membuat karyawan atau tenaga kerja borongan dalam keadaan suasana senang dan nyaman agar dalam melakukan produksi rokok diharapkan menghasilkan produk yang sesuai spesifikasi dan menekan ketidaksesuaian. Namun dalam menilai kinerja karyawan, perusahaan belum mengetahui indikator-indikator yang dapat digunakan sebagai alat ukur sehingga perlu dilakukan analisis indikator-indikator yang mempengaruhi kinerja karyawan.

Sumber Daya Manusia (SDM) merupakan elemen utama organisasi dibandingkan elemen lain sebab manusia itu sendiri yang mengendalikan elemen yang lain tersebut. Oleh karena itu, pengelolaan sumber daya manusia dalam organisasi menjadi suatu hal yang sangat penting. Pengelolaan sumber daya manusia dalam organisasi menjadi suatu bidang ilmu yang dikenal dengan Manajemen Sumber Daya Manusia (MSDM) yang merupakan program, aktivitas untuk mendapatkan sumber daya manusia, mengembangkan, memelihara, dan mendayagunakan untuk mendukung organisasi mencapai tujuannya. Perusahaan perlu melakukan penilaian kinerja karyawan secara periodik untuk memberikan feedback kepada pegawai dalam upaya memperbaiki tampilan kerjanya dan meningkatkan produktivitas perusahaan [1]. Adapun faktor-faktor yang mempengaruhi kinerja individu tenaga kerja yaitu kemampuan diri, motivasi, dukungan yang diterima, keterlibatan pekerjaan, dan hubungan mereka dengan organisasi [2].

Proses produksi di unit Karangbener terdapat 4.281 karyawan yang terbagi dalam 3 proses produksi yaitu 3.389 karyawan proses giling yang meliputi 1.680 karyawan giling dan 1.709 karyawan batil, 828 karyawan proses pak, dan 64 karyawan proses press. Seringkali ketidaksesuaian terhadap hasil produksi terjadi pada proses giling dikarenakan proses ini merupakan aktivitas pembuatan rokok batang secara manual sebelum di-pak pada proses selanjutnya. Oleh karena itu, penelitian ini dilakukan untuk mengetahui faktorfaktor apa saja yang mempengaruhi karyawan PT Djarum Unit Karangbener, Kudus-Jawa Tengah pada proses giling. Beberapa faktor yang diduga mempengaruhi kinerja karyawan antara lain kemampuan diri, motivasi, dan dukungan sosial. Tujuan dalam penelitian ini yaitu memodelkan faktor-faktor yang mempengaruhi kinerja karyawan bagian produksi rokok di PT Djarum Unit Karangbener, Kudus-Jawa Tengah dengan menggunakan 3 faktor tersebut.

Penelitian tentang analisis pengaruh disiplin, keterampilan, kompensasi dan masa kerja terhadap kinerja karyawan harian Administration and General Service di PT Djarum Primary Kudus menggunakan regresi linear 
berganda menyatakan bahwa disiplin dan keterampilan berpengaruh terhadap kinerja karyawan [3]. Penelitian tentang pengaruh kepemimpinan dan motivasi terhadap kinerja karyawan pada unit SKT Brak BL 53 PT Djarum Kudus menggunakan regresi linear berganda menyatakan bahwa terdapat pengaruh positif dari kedua variabel terhadap kinerja karyawan [4]. Penelitian tentang analisis keterlibatan kerja dan dukungan organisasi terhadap kinerja dengan mediasi komitmen organisasional dosen Politeknik Negeri Semarang menggunakan regresi linear berganda menyatakan bahwa keterlibatan kerja dan dukungan organisasi berpengaruh positif dan signifikan terhadap kinerja dosen [5].

\section{TINJAUAN PUSTAKA}

\section{A. Stuctural Equation Modeling}

Structural Equation Modeling (SEM) merupakan gabungan dari dua metode statistik yang terpisah yaitu analisis faktor yang dikembangkan di ilmu psikologi dan psikometri dengan model persamaan simultan yang dikembangkan di ekonometrika [6]. SEM dapat menguji secara bersama-sama yaitu menguji model persamaan struktural yang merupakan hubungan antara variabel laten independen dan dependen kemudian menguji model pengukuran yang merupakan hubungan (nilai loading) antara variabel indikator (observasi) dengan variabel laten. Hubungan ini dinyatakan dengan faktor loading yang menunjukkan besarnya korelasi antara indikator dengan variabel laten yang dijelaskannya [7].

\section{Model Struktural}

Model Struktural adalah hubungan antara variabel laten (construct) independen (eksogen) dan dependen (endogen). Variabel laten endogen adalah variabel laten yang menjadi variabel tak bebas dalam satu persamaan, meskipun dalam persamaan lain (di dalam model tersebut) menjadi variabel bebas. Variabel laten eksogen adalah variabel laten yang berperan sebagai variabel bebas dalam model. Pola hubungan antar variabel laten dalam model struktural ini dianalisis dengan pendekatan Path Analysis yang identik dengan Analisis Regresi. Model umum persamaan struktural ditunjukkan pada persamaan 2.1.

$$
\boldsymbol{\eta}_{(m x 1)}=\boldsymbol{\beta}_{(m x m)} \boldsymbol{\eta}_{(m x 1)}+\boldsymbol{\Gamma}_{(m x l)} \boldsymbol{\xi}_{(l x 1)}+\boldsymbol{\zeta}_{(m x 1)}
$$

dimana,

$\boldsymbol{\eta}=$ Eta, Variabel laten endogen

$\boldsymbol{\beta}=$ Beta, Koefisien variabel laten endogen

$\boldsymbol{\Gamma}=$ Kapital gamma, Koefisien variabel laten eksogen

$\xi=\mathrm{Xi}$, Variabel laten eksogen

$\zeta \quad=$ Zeta, Error model

$m$ = Banyaknya variabel laten endogen

$l \quad=$ Banyaknya variabel laten eksogen

2. Model Pengukuran

Variabel laten merupakan variabel tak teramati atau tak dapat diukur secara langsung. Model pengukuran adalah bagian dari suatu model persamaan struktural yang menggambarkan hubungan variabel laten dengan indikatorindikatornya yang dinyatakan dalam loading factor $(\lambda)$. Model pengukuran merepresentasikan dugaan hipotesis yang sudah ada sebelumnya yaitu hubungan antara indikator-indikator dengan faktornya yang dievaluasi dengan menggunakan teknik analisis faktor konfirmatori atau Confirmatori Faktor Analysis (CFA) [8].

\section{B. Asumsi Structural Equation Modeling}

Terdapat beberapa asumsi yang harus dipenuhi pada analisis Structural Equation Modeling (SEM) yang dijelaskan sebagai berikut.

1. Ukuran Sampel

Ukuran sampel yang digunakan dalam analisis SEM berdasarkan karakteristik model struktural dan model pengukuran adalah minimal 100 jika model menggunakan variabel laten sebanyak 5 atau lebih, variabel teramati sebanyak lebih dari 3 indikator [7].

\section{Distribusi Normal Multivariat}

Distribusi normal multivariat merupakan pengembangan dari distribusi normal univariat dengan jumlah variabel lebih dari satu. Distribusi ini digunakan pada sekelompok data yang variabel-variabelnya saling dependen. Fungsi densitas peluangnya ditunjukkan pada persamaan 2 [9].

$$
f(\mathbf{x})=\frac{1}{(2 \pi)^{p / 2}|\boldsymbol{\Sigma}|} e^{-\frac{1}{2}(\mathbf{x}-\boldsymbol{\mu})^{\prime} \boldsymbol{\Sigma}^{-1}(\mathbf{x}-\boldsymbol{\mu})},-\infty<\mathbf{x}<\infty
$$

Pemeriksaan distribusi multivariat normal dapat dilakukan dengan cara membuat $q-q$ plot. $q-q$ plot akan membentuk sebuah garis lurus jika sebaran data mengikuti distribusi multivariat normal dimana sebanyak sekitar 50\% nilai-nilai dari $\mathrm{d}_{\mathrm{k}}^{2}<\mathrm{q}$.

Selain itu, pengujian multivariat normal juga dapat dilakukan dengan menggunakan metode korelasi dengan hipotesis sebagai berikut.

Hipotesis:

$\mathrm{H}_{0} \quad: \mathrm{F}(\mathrm{x})=\mathrm{F}_{0}(\mathrm{x})$ (Data berdistribusi multivariat normal)

$\mathrm{H}_{1}: \mathrm{F}(\mathrm{x}) \neq \mathrm{F}_{0}(\mathrm{x})$ (Data tidak berdistribusi multivariat normal)

Statistik uji :

$$
r_{Q}=\frac{\sum_{j=1}^{n}\left(x_{(k)}-\bar{x}\right)\left(q_{(k)}-\bar{q}\right)}{\sqrt{\sum_{k=1}^{n}\left(x_{(k)}-\bar{x}\right)^{2}} \sqrt{\sum_{k=1}^{n}\left(q_{(k)}-\bar{q}\right)^{2}}}
$$

Keputusan :

$\mathrm{H}_{0}$ ditolak jika $r_{\mathrm{Q}}<$ critical point dimana nilai critical point.

\section{Confirmatory Factor Analysis (CFA)}

CFA merupakan metode yang digunakan untuk menguji measurement model yang menggambarkan hubungan antara variabel laten dengan indikator-indikatornya yang dinyatakan dalam loading factor $(\lambda)$. CFA juga dapat digunakan untuk menguji pertanyaan dalam kuesioner apakah sudah representatif (valid) dan benar-benar akurat atau konsisten (reliabel).

1. Validitas

Signifikansi indikator-indikator dalam mengukur variabel laten dapat diketahui dengan menggunakan statistik uji t karena loading factor $\left(\lambda_{\mathrm{i}}\right)$ dalam CFA menggunakan standardized estimate.

$$
t_{\text {hitung }}=\frac{\hat{\lambda}_{i}}{S E\left(\hat{\lambda}_{i}\right)}
$$

Jika nilai $\left|\mathrm{t}_{\text {hitung }}\right|<\mathrm{t}_{(\alpha / 2 \text {,df })}$ maka gagal tolak $\mathrm{H}_{0}$ dan dapat disimpulkan bahwa $\lambda_{\mathrm{i}}$ tidak signifikan dalam mengukur atau membentuk variabel laten.

\section{Reliabilitas}

Reliabilitas adalah konsistensi suatu pengukuran. Reliabilitas variabel laten dapat diketahui dengan menghitung nilai coefficient reliability $\left(p_{c}\right)$. 


$$
\hat{\rho}_{c}=\frac{\left(\sum_{i=1}^{p} \hat{\lambda}_{i}\right)^{2}}{\left[\left(\sum_{i=1}^{p} \hat{\lambda}_{i}\right)^{2}+\left(\sum_{i=1}^{p} \hat{\delta}_{i}\right)\right]}
$$

Variabel laten dikatakan reliabel jika memiliki nilai coefficient reliability $\geq 0,7$ namun jika nilai $C R \geq 0,6$ masih dapat dikatakan reliabel [7].

\section{Identifikasi Model}

Identifikasi model digunakan untuk mengetahui informasi yang cukup untuk mengidentifikasi persamaan model. Identifikasi model berkaitan dengan membandingkan jumlah persamaan yang ada dengan banyak parameter yang ditaksir [7]. Model dikatakan under-identified jika memiliki derajat bebas negatif, jika derajat bebas sama dengan 0 model dikatakan just-identified, sedangkan jika derajat bebas positif maka model dikatakan over-identified sehingga generalisasi dapat dilakukan untuk mendapatkan model yang paling sesuai.

\section{E. Kesesuaian Model}

Indikator kesesuaian model pengukuran (measurement model) dan model struktural (structural model) dapat dilihat dari indeks-indeks pengukuran antara lain Chi-Square Statistic, Goodnest of Fit Index (GFI), Adjusted Goodnest of Fit Index (AGFI), The Root Mean Square Error of Approximation (RMSEA), dan Comparative Fit Index (CFI). Nilai kritis untuk indikator-indikator kesesuaian model adalah sebagai berikut [7].

Tabel 1.

Goodness of Fit Statistics Indeces

\begin{tabular}{lc}
\multicolumn{2}{c}{ Goodness of Fit Statistics Indeces } \\
\hline \hline \multicolumn{1}{c}{ Goodness of Fit Test } & Cut Off Value \\
\hline Chi-square & Diharapkan kecil \\
P-value & $\geq 0,05$ \\
GFI & $\geq 0,90$ \\
RMSEA & $\leq 0,08$ \\
TLI & $\geq 0,90$ \\
CFI & $\geq 0,90$ \\
AGFI & $\geq 0,90$ \\
\hline \hline
\end{tabular}

\section{F. Estimasi Parameter SEM}

Metode yang sering digunakan untuk mengestimasi parameter pada SEM adalah Maximum Likelihood Estmation (MLE) [10]. Misalkan N sampel random yang identik dan independen dari variabel random $Z$ yang berdistribusi multivariat normal dengan mean 0 dan varians $\Sigma$, maka fungsi kepadatan peluang $Z_{\mathrm{i}}(i=1,2, \ldots, \mathrm{N})$ adalah $f\left(Z_{i} ; \theta\right)$. Estimator FML yaitu sebagai berikut.

$$
F_{M L}=\log \left|\sum(\theta)\right|+\operatorname{tr}\left(S \Sigma^{-1}(\theta)\right)-\log |S|-(p+q)
$$

\section{G. Kinerja Karyawan}

Performance atau kinerja adalah hasil kerja yang dapat dicapai oleh seseorang atau kelompok orang dalam suatu perusahaan sesuai dengan wewenang dan tanggung jawab masing-masing dalam upaya pencapaian tujuan perusahaan secara legal, tidak melanggar hukum dan tidak bertentangan dengan moral dan etika. Kinerja karyawan adalah tingkatan para karyawan mencapai persyaratan-persyaratan pekerjaan [11]. Adapun faktor-faktor yang mempengaruhi kinerja karyawan yaitu kemampuan diri, motivasi, dukungan yang diterima, keterlibatan pekerjaan, dan hubungan mereka dengan organisasi [2].

\section{H. Kemampuan Diri}

Kemampuan adalah bakat seseorang untuk melakukan tugas mental atau fisik. Kemampuan kerja adalah suatu kapasitas individu untuk mengerjakan berbagai tugas dalam suatu pekerjaan [12]. Kemampuan karyawan dipengaruhi oleh tingkat pendidikan, latihan, motivasi, etos kerja, mental dan kemampuan fisik karyawan yang bersangkutan [12].

\section{Motivasi}

Motivasi adalah suatu keahlian dalam mengarahkan pegawai dan organisasi agar mau bekerja, sehingga keinginan para pegawai dan tujuan organisasi sekaligus tercapai [13]. Motivasi kerja terdiri dari dua jenis yaitu intrinsik dan ekstrinsik. Seseorang yang secara intrinsik termotivasi karena menikmati setiap tugas dan merasa tertantang untuk menyelesaikan setiap tugas yang dimiliki. Anggota yang termotivasi secara ekstrinsik pada umumnya tidak terlalu menikmati tugas yang dimiliki tetapi tetap termotivasi untuk mendapatkan imbalan dan pujian atas sebuah pencapaian ataupun menghindari konsekuensi negatif.

\section{J. Dukungan Sosial}

Dukungan sosial adalah dukungan atau bantuan yang berasal dari orang lain seperti teman, keluarga, tetangga, rekan kerja dan orang lain. Dukungan sosial adalah kenyamanan, perhatian, penghargaan, maupun bantuan dalam bentuk lainnya yang diterima individu dari orang lain ataupun dari kelompok [14]. Penelitian ini mencakup dukungan sosial (social support) yang diberikan oleh supervisor dan rekan kerja di PT Djarum Unit Karangbener, Kudus-Jawa Tengah.

\section{K. Kerangka Konsep}

Kerangka konsep dengan 5 hipotesis dugaan dari 3 model struktural pada penelitian ini adalah sebagai berikut.

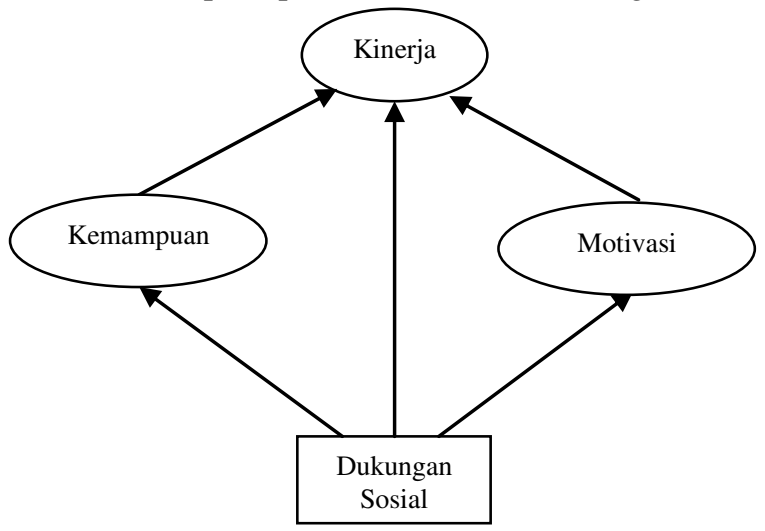

Gambar 1. Kerangka Konsep Penelitian.

Berdasarkan kerangka konsep pada Gambar 1, diperoleh beberapa hipotesis yang dapat digunakan dalam penelitian ini sebagai berikut.

1. Hipotesis 1 : Dukungan sosial berpengaruh signifikan terhadap motivasi

2. Hipotesis 2 : Dukungan sosial berpengaruh signifikan terhadap kemampuan diri

3. Hipotesis 3 : Kemampuan diri berpengaruh signifikan terhadap kinerja karyawan

4. Hipotesis 4 : Motivasi berpengaruh signifikan terhadap kinerja karyawan

5. Hipotesis 5 : Dukungan sosial berpengaruh signifikan terhadap kinerja karyawan 
Teori pendukung dari hipotesis 1 yaitu terdapat 10 faktor yang dapat mendorong motivasi kerja, 2 diantaranya adalah teman sekerja dan perilaku atasan yang akan mempengaruhi motivasi kerja karyawan [15]. Teori pendukung dari hipotesis 2 yaitu salah satu faktor yang dapat menghambat kemampuan seorang pegawai adalah menganggap faktor hubungan manusia manusiawi sia-sia diterapkan [16]. Teori pendukung hipotesis 3 hingga 5 yaitu faktor-faktor yang mempengaruhi kinerja karyawan antara lain kemampuan diri, motivasi, dukungan yang diterima, keterlibatan pekerjaan, dan hubungan mereka dengan organisasi [2].

\section{METODOLOGI PENELITIAN}

\section{A. Teknik Pengambilan Sampel}

Data yang digunakan pada penelitian ini adalah data primer yang dilakukan melalui survey secara langsung pada karyawan PT Djarum Unit Karangbener, Kudus-Jawa Tengah pada proses giling yang terdiri dari bagian giling dan batil. Populasi dalam penelitian ini sebanyak 3.389 karyawan yang terdiri dari 1.680 bagian giling dan 1.709 bagian batil. Jumlah sampel pada penelitian ini didasarkan perhitungan metode sampel yang digunakan yaitu Simple Random Sampling (SRS). Berdasarkan perhitungan dengan menggunakan taraf signifikan $(\alpha)$ sebesar 5\% dan estimasi batas kesalahan (B) sebesar 0,092 maka diperoleh jumlah sampel sebanyak 110 karyawan dimana bagian giling sebanyak 55 karyawan dan bagian batil sebanyak 55 karyawan.

\section{B. Variabel Penelitian}

Variabel yang digunakan dalam penelitian ini adalah kemampuan diri, motivasi, dan dukungan sosial terhadap kinerja karyawan produksi di PT Djarum Unit Karangbener, Kudus-Jawa Tengah pada proses giling. Variabel penelitian ini menggunakan skala likert 1-7 dimana 1 (sangat tidak setuju), 2 (tidak setuju), 3 (kurang setuju), 4 (raguragu/antara setuju atau tidak), 5 (agak setuju), 6 (setuju), dan 7 (sangat setuju). Adapun rincian banyaknya indikator pada masing-masing variabel penelitian adalah sebagai berikut.

Tabel 2.

Jumlah indikator tiap variabel laten

\begin{tabular}{ccc} 
& Jumlah indikator tiap variabel laten \\
\hline \hline Variabel & Keterangan & Banyaknya Indikator \\
\hline $\mathrm{Y}$ & Kinerja Karyawan & 4 butir \\
$\mathrm{X}_{1}$ & Kemampuan Diri & 6 butir \\
$\mathrm{X}_{2}$ & Motivasi & 6 butir \\
$\mathrm{X}_{3}$ & Dukungan Sosial & $10 \mathrm{butir}$ \\
\hline \hline
\end{tabular}

\section{Langkah Analisis}

Langkah anaisis data dalam penelitian ini adalah sebagai berikut.

1. Mengumpulkan data melalui survey secara langsung pada karyawan PT Djarum Unit Karangbener, KudusJawa Tengah pada proses giling.

2. Mendeskripsikan karakteristik data dengan statistika deskriptif menggunakan pie chart.

3. Menganalisis indikator-indikator pada masing-masing variabel laten menggunakan CFA.

a. Melakukan pemeriksaan asumsi ukuran sampel dan distribusi multivariat normal.

b. Melakukan identifikasi model.

c. Melakukan pengujian dan pemeriksaan kebaikan model.

d. Melakukan pengujian keakuratan parameter.

4. Memodelkan faktor-faktor yang mempengaruhi kinerja karyawan menggunakan SEM. a. Membuat konseptualisasi model dan teori sesuai dengan kerangka konsep yang telah dijelaskan sebelumnya.

b. Melakukan pemodelan dari kerangka konsep dengan membuat hipotesis yang telah dijelaskan sebelumnya.

c. Membuat persamaan struktural sesuai dengan diagram path antar variabel laten dan indikatorindikatornya.

Kemampuan $\left(\eta_{1}\right)=\gamma_{11} *$ dukungan $\operatorname{sosial}\left(\xi_{1}\right)+\zeta_{1}$

Motivasi $\left(\eta_{2}\right)=\gamma_{12} *$ dukungan $\operatorname{sosial}\left(\xi_{1}\right)+\zeta_{2}$

Kinerja $\left(\eta_{3}\right) \quad=\beta_{13}$ kemampuan diri $\left(\eta_{1}\right)+\beta_{23} *$

$\operatorname{motivasi}\left(\eta_{2}\right)+\gamma_{13} *$ dukungan $\operatorname{sosial}\left(\xi_{1}\right)+\zeta_{3}$

d. Melakukan identifikasi model struktural.

e. Melakukan pengujian dan pemeriksaan kebaikan model.

f. Melakukan pengujian keakuratan parameter.

5. Menginteprestasi hasil analisis

6. Menarik kesimpulan.

\section{ANALISIS DAN PEMBAHASAN}

\section{A. Karakteristik Karyawan}

Terdapat beberapa data diri karyawan yang dapat diidentifikasi karakteristiknya. Hal ini bertujuan untuk menggambarkan latar belakang karyawan yang bekerja di PT Djarum Unit Karangbener, Kudus. Adapun analisisnya menggunakan statistika deskriptif berupa visualisasi ditunjukkan pada Gambar 2 berikut.

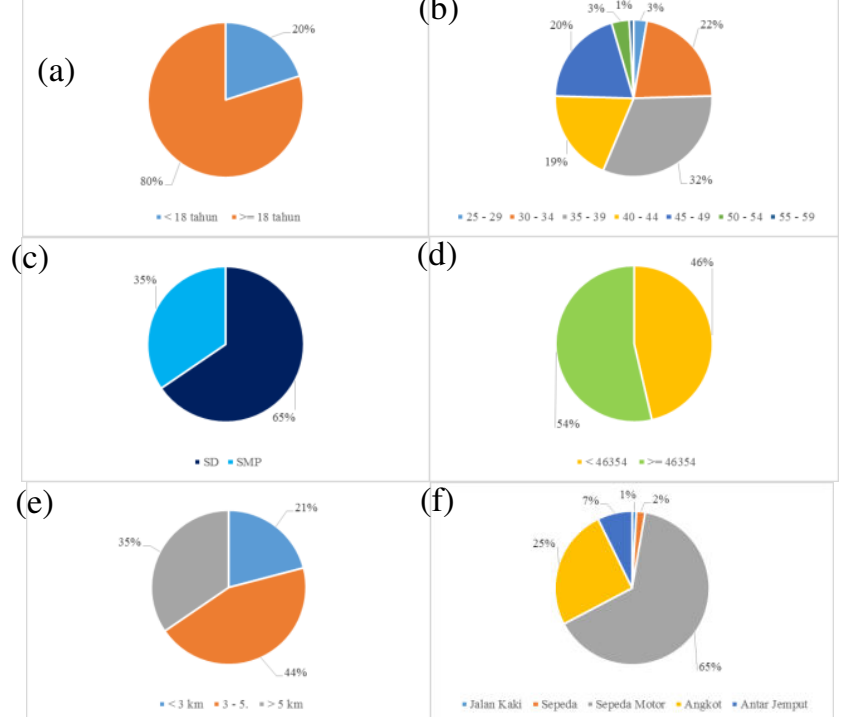

Gambar 2.(a) Masa kerja (b) Usia (c) Pendidikan terakhir (d) Rata-rata upah per hari (e) Jarak rumah ke tempat kerja (d) Moda transportasi.

Karakteristik karyawan proses giling di PT Djarum Unit Karangbener, Kudus mayoritas sudah bekerja lebih dari 18 tahun dimana karyawan berada pada rentang usia 35-39 tahun dengan pendidikan terakhir yang ditempuh adalah tingkat SD/MI/sederajat dan upah yang diterima karyawan mayoritas lebih dari rata-rata sebesar $\mathrm{Rp}$ 46.354,00. Mayoritas karyawan kesehariannya memilih transportasi berupa sepeda motor dimana para karyawan memiliki jarak rumah ke tempat kerja berkisar antara 3-5 km.

\section{B. Pemeriksaan Asumsi}

Terdapat 2 asumsi yang harus dipenuhi dalam analisis Structural Equation Modeling (SEM) yaitu ukuran sampel dan data berdistribusi multivariat normal. Diketahui bahwa 
sampel yang digunakan dalam penelitian ini sebanyak 110 responden sehingga dapat dikatakan sudah memenuhi asumsi ukuran sampel.

Selanjutnya dilakukan pemeriksaan dan pengujian distribusi multivariat normal. Pada pemeriksaan diketahui nilai proporsi sebesar $56,73 \%$ dimana nilai tersebut masih berada di sekitar 50\% sehingga dapat dikatakan bahwa data telah berdistribusi multivariat normal. Namun pada pengujian diperoleh nilai $r_{Q}$ sebesar 0,956 dimana nilai tersebut lebih kecil dari critical point sebesar 0,98762 artinya data tidak berdistribusi multivariat normal. Ditinjau kembali, pada pemeriksaan data telah berdistribusi normal dan pada pengujian diketahui bahwa nilai $r_{Q}$ tidak jauh berbeda dengan nilai critical point sehingga disimpulkan bahwa data mendekati distribusi multivariat normal.

\section{Confirmatory Factor Analysis (CFA)}

Analisis indikator-indikator setiap variabel laten menggunakan CFA dijelaskan sebagai berikut.

1. Variabel Kinerja Karyawan

Hasil analisis CFA untuk variabel kinerja karyawan dimana telah memenuhi kriteria kesesuaian model ditunjukkan pada Gambar 3 berikut.

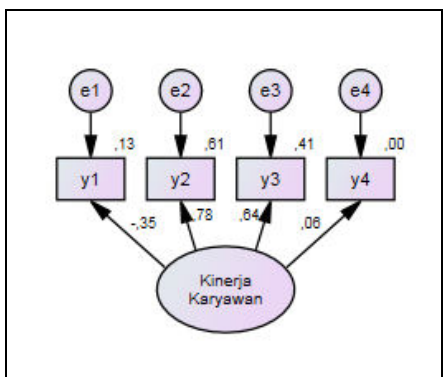

Gambar 3. Model CFA kinerja karyawan.

Berdasarkan model CFA variabel kinerja karyawan pada Gambar 3, diperoleh nilai goodness of fit test yang telah sesuai, sehingga hasil estimasi parameternya ditunjukkan pada Tabel 3 berikut.

Tabel 3.

Estimasi parameter variabel kinerja karyawan

\begin{tabular}{cccl}
\hline \hline Indikator & Loading Factor & P-value & \multicolumn{1}{c}{ Keterangan } \\
\hline $\mathrm{A}_{1}$ & $-0,354$ & 0,006 & Signifikan \\
$\mathrm{A}_{2}$ & 0,781 & 0,013 & Signifikan \\
$\mathrm{A}_{3}$ & 0,643 & 0,000 & Signifikan \\
$\mathrm{A}_{4}$ & 0,056 & 0,641 & Tidak Signifikan \\
\hline \hline
\end{tabular}

Tabel 3 menunjukkan bahwa diperoleh keputusan $\mathrm{H}_{0}$ ditolak pada indikator $\mathrm{A}_{1}, \mathrm{~A}_{2}$, dan $\mathrm{A}_{3}$. Artinya, ketiga indikator tersebut signifikan dalam mengukur variabel kinerja karyawan. Dikarenakan variabel $\mathrm{A}_{4}$ tidak signifikan maka tidak diikutsertakan pada analisis selanjutnya. Indikator yang memberikan pengaruh paling besar terhadap variabel kinerja karyawan adalah $\mathrm{A}_{2}$ yaitu "saya berhasil memproduksi rokok yang berkualitas baik". Selain itu, berdasarkan hasil perhitungan diperoleh nilai construct reliability (CR) sebesar 0,631. Hal ini menunjukkan bahwa tingkat konsistensi atau akurasi pada variabel kinerja karyawan mendekati atau cukup reliabel.

2. Variabel Kemampuan Diri

Hasil analisis CFA untuk variabel kemampuan diri dimana telah memenuhi kriteria kesesuaian model ditunjukkan pada Gambar 4 berikut.

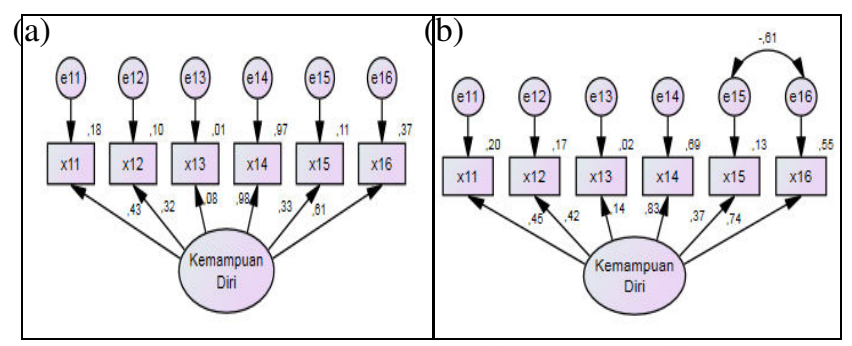

Gambar 4. (a) Model CFA kemampuan diri sebelum modifikasi (b) Mode CFA kemampuan diri setelah modifikasi.

Berdasarkan model CFA variabel kemampuan diri pada Gambar 4, diperoleh nilai goodness of fit test yang telah sesuai yaitu setelah modifikasi, sehingga hasil estimasi parameternya ditunjukkan pada Tabel 4 berikut.

Tabel 4.

Estimasi parameter variabel kemampuan diri

\begin{tabular}{cccl}
\hline \hline Indikator & Loading Factor & P-value & \multicolumn{1}{c}{ Keterangan } \\
\hline $\mathrm{B}_{1}$ & 0,451 & 0,000 & Signifikan \\
$\mathrm{B}_{2}$ & 0,418 & 0,000 & Signifikan \\
$\mathrm{B}_{3}$ & 0,136 & 0,204 & Tidak Signifikan \\
$\mathrm{B}_{4}$ & 0,830 & 0,000 & Signifikan \\
$\mathrm{B}_{5}$ & 0,366 & 0,007 & Signifikan \\
$\mathrm{B}_{6}$ & 0,742 & 0,000 & Signifikan \\
\hline \hline
\end{tabular}

Tabel 4 menunjukkan bahwa diperoleh keputusan $\mathrm{H}_{0}$ ditolak pada indikator $\mathrm{B}_{1}, \mathrm{~B}_{2}, \mathrm{~B}_{4}, \mathrm{~B}_{5}$, dan $\mathrm{B}_{6}$. Artinya, kelima indikator tersebut signifikan dalam mengukur variabel kemampuan diri. Dikarenakan variabel $\mathrm{B}_{3}$ tidak signifikan maka tidak diikutsertakan pada analisis selanjutnya. Indikator yang memberikan pengaruh paling besar terhadap variabel kinerja karyawan adalah $\mathrm{B}_{4}$ yaitu "saya memfokuskan semua tenaga pada pekerjaan". Selain itu, berdasarkan hasil perhitungan diperoleh nilai construct reliability (CR) sebesar 0,708 . Hal ini menunjukkan bahwa tingkat konsistensi atau akurasi pada variabel kemampuan diri sudah reliabel.

3. Variabel Motivasi

Hasil analisis CFA untuk variabel motivasi dimana telah memenuhi kriteria kesesuaian model ditunjukkan pada Gambar 5 berikut.

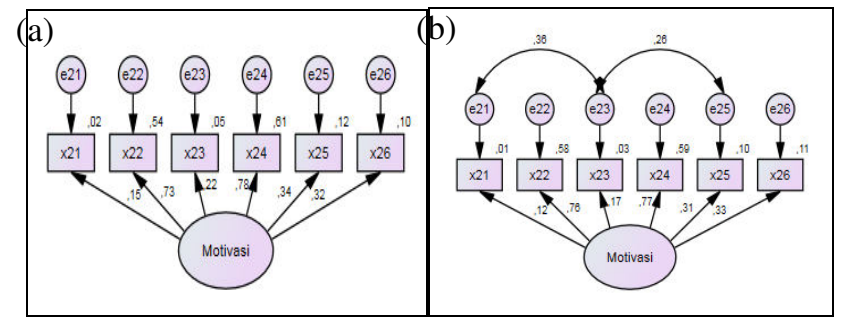

Gambar 5. (a) Model CFA motivasi sebelum modifikasi (b) Model CFA motivasi setelah modifikasi.

Berdasarkan model CFA variabel motivasi pada Gambar 5, diperoleh nilai goodness of fit test yang telah sesuai yaitu setelah modifikasi, sehingga hasil estimasi parameternya ditunjukkan pada Tabel 5 berikut.

Tabel 5.

Estimasi parameter variabel motivasi

\begin{tabular}{cccl}
\hline \hline Indikator & Loading Factor & P-value & \multicolumn{1}{c}{ Keterangan } \\
\hline $\mathrm{C}_{1}$ & 0,115 & 0,320 & Tidak Signifikan \\
$\mathrm{C}_{2}$ & 0,759 & 0,000 & Signifikan \\
$\mathrm{C}_{3}$ & 0,167 & 0,165 & Tidak Signifikan \\
$\mathrm{C}_{4}$ & 0,769 & 0,000 & Signifikan \\
$\mathrm{C}_{5}$ & 0,308 & 0,038 & Signifikan \\
$\mathrm{C}_{6}$ & 0,331 & 0,004 & Signifikan \\
\hline \hline
\end{tabular}


Tabel 5 menunjukkan bahwa diperoleh keputusan $\mathrm{H}_{0}$ ditolak pada indikator $\mathrm{C}_{2}, \mathrm{C}_{4}, \mathrm{C}_{5}$, dan $\mathrm{C}_{6}$. Artinya, keempat indikator tersebut signifikan dalam mengukur variabel motivasi. Dikarenakan variabel $\mathrm{C}_{1}$ dan $\mathrm{C}_{3}$ tidak signifikan maka tidak diikutsertakan pada analisis selanjutnya. Indikator yang memberikan pengaruh paling besar terhadap variabel kinerja karyawan adalah $\mathrm{C}_{4}$ yaitu "pekerjaan ini memungkinkan saya mendapat uang yang banyak". Selain itu, berdasarkan hasil perhitungan diperoleh nilai construct reliability (CR) sebesar 0,641. Hal ini menunjukkan bahwa tingkat konsistensi atau akurasi pada variabel motivasi mendekati atau cukup reliabel.

4. Variabel Dukungan Sosial

Hasil analisis CFA untuk variabel dukungan sosial dimana telah memenuhi kriteria kesesuaian model ditunjukkan pada Gambar 6 berikut.

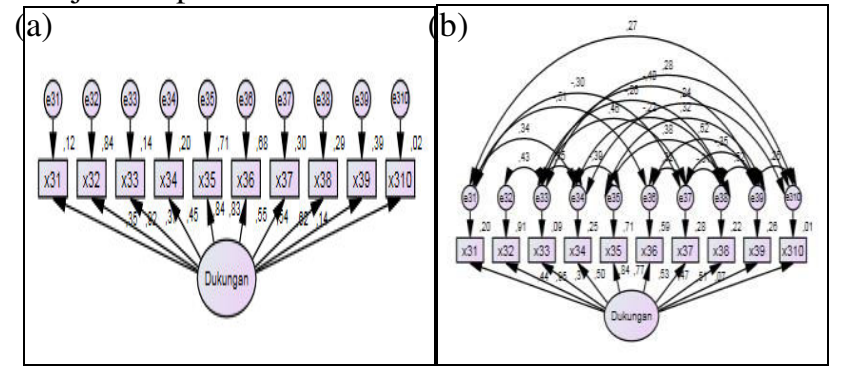

Gambar 6.(a) Model CFA dukungan sosial sebelum modifikasi (b) Model CFA dukungan sosial setelah modifikasi.

Berdasarkan model CFA variabel dukungan sosial pada Gambar 6, diperoleh nilai goodness of fit test yang telah sesuai yaitu setelah modifikasi, sehingga hasil estimasi parameternya ditunjukkan pada Tabel 6 berikut.

Tabel 6.

Estimasi parameter variabel dukungan sosial

\begin{tabular}{cccl}
\hline \hline Indikator & Loading Factor & P-value & \multicolumn{1}{c}{ Keterangan } \\
\hline $\mathrm{D}_{1}$ & 0,443 & 0,000 & Signifikan \\
$\mathrm{D}_{2}$ & 0,952 & 0,000 & Signifikan \\
$\mathrm{D}_{3}$ & 0,305 & 0,003 & Signifikan \\
$\mathrm{D}_{4}$ & 0,505 & 0,000 & Signifikan \\
$\mathrm{D}_{5}$ & 0,843 & 0,000 & Signifikan \\
$\mathrm{D}_{6}$ & 0,768 & 0,000 & Signifikan \\
$\mathrm{D}_{7}$ & 0,531 & 0,000 & Signifikan \\
$\mathrm{D}_{8}$ & 0,470 & 0,000 & Signifikan \\
$\mathrm{D}_{9}$ & 0,506 & 0,000 & Signifikan \\
$\mathrm{D}_{10}$ & 0,074 & 0,466 & Tidak Signifikan \\
\hline \hline
\end{tabular}

Tabel 6 menunjukkan bahwa diperoleh keputusan $\mathrm{H}_{0}$ ditolak pada indikator semua indikator kecuali indikator $\mathrm{D}_{10}$. Artinya, kesembilan indikator tersebut signifikan dalam mengukur variabel dukungan sosial. Dikarenakan variabel $\mathrm{D}_{10}$ tidak signifikan maka tidak diikutsertakan pada analisis selanjutnya. Indikator yang memberikan pengaruh paling besar terhadap variabel kinerja karyawan adalah $\mathrm{D}_{2}$ yaitu "ada seorang rekan kerja dimana saya bisa bercerita ketika saya merasa sedih tanpa merasa canggung atau sungkan". Selain itu, berdasarkan hasil perhitungan diperoleh nilai construct reliability (CR) sebesar 0,838. Hal ini menunjukkan bahwa tingkat konsistensi atau akurasi pada variabel dukungan sosial sudah reliabel.

\section{Analisis Structural Equation Modeling (SEM)}

Langkah selanjutnya melakukan analisis terhadap model struktural menggunakan Strutural Equation Modeling (SEM) untuk mengetahui hubungan keterkaitan antar variabel laten. Terdapat 3 model dugaan yang telah dijelaskan sebelumnya. Model struktral dari analisis SEM ditunjukkan pada Gambar 7 berikut.

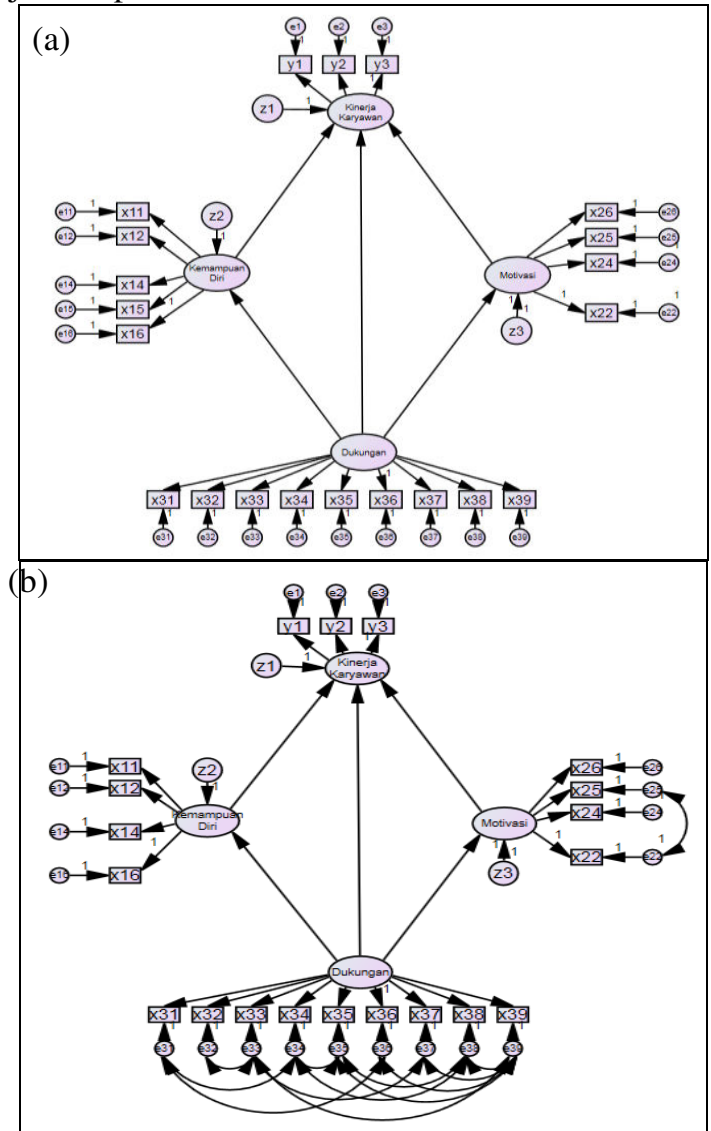

Gambar 7. (a) Model struktural SEM sebelum modifikasi (b) Model struktural SEM sesudah modifikasi.

Berdasarkan Gambar 7(a) dan 7(b) ternyata model masih belum sesuai namun model tidak dapat dimodifikasi lagi sehingga dilakukan perbandingan kesesuaian model antara model sebelum dan setelah modifikasi yang ditunjukkan pada Tabel 9 berikut.

Tabel 9

Goodness of Fit perbandingan model struktural

\begin{tabular}{lcc}
\hline \hline Kriteria Kesesuaian Model & $\begin{array}{c}\text { Sebelum } \\
\text { Modifikasi }\end{array}$ & $\begin{array}{c}\text { Setelah } \\
\text { Modifikasi }\end{array}$ \\
\hline Chi-Square & 1061,543 & 649,875 \\
P-value & 0,000 & 0,000 \\
GFI & 0,591 & 0,709 \\
RMSEA & 0,213 & 0,176 \\
TLI & 0,311 & 0,532 \\
CFI & 0,386 & 0,618 \\
AGFI & 0,495 & 0,606 \\
\hline \hline
\end{tabular}

Berdasarkan Tabel 9 diperoleh hasil bahwa model setelah dimodifikasi memiliki kriteria kesesuaian model lebih baik daripada sebelum modifikasi sehingga model yang digunakan adalah model setelah dimodifikasi. Hasil signifikasi estimasi parameternya ditunjukkan pada Tabel 10 berikut.

Tabel 10

Estimasi parameter model struktural

\begin{tabular}{lcc}
\hline \hline \multicolumn{1}{c}{ Model Dugaan } & Estimasi & P-value \\
\hline Dukungan $\rightarrow$ Kemampuan & 0,191 & 0,081 \\
Dukungan $\rightarrow$ Motivasi & 0,622 & $0,000^{*}$ \\
Dukungan $\rightarrow$ Kinerja & $-0,237$ & 0,181 \\
Motivasi $\rightarrow$ Kinerja & 0,556 & $0,012^{*}$ \\
Kemampuan $\rightarrow$ Kinerja & 0,598 & $0,000^{*}$ \\
\hline \hline
\end{tabular}

* Signifikan pada taraf signifikan 0,05

Tabel 10 menunjukkan terdapat 3 model dugaan yang signifikan, sedangkan 2 model dugaan lainnya tidak 
signifikan. Ketiga model yang signifikan memiliki nilai loading factor yang positif. Jika diinterpretasikan yaitu semakin tinggi variabel laten yang mempengaruhi maka variabel laten yang dipengaruhi juga semakin tinggi, dan sebaliknya.

Penjelasan diatas merupakan pengujian model struktural dengan pengaruh secara langsung (direct effect). Langkah selanjutnya yaitu menganalisis pola hubungan model struktural dengan pengaruh secara tidak langsung (indirect effect). Diketahui bahwa terdapat 2 hipotesis dugaan pengaruh tidak langsung yaitu sebagai berikut.

Hipotesis A : Terdapat pengaruh tidak langsung dari dukungan sosial terhadap kinerja karyawan melalui kemampuan diri.

Hipotesis B : Terdapat pengaruh tidak langsung dari dukungan sosial terhadap kinerja karyawan melalui motivasi.

Hasil analisis pengaruh secara tidak langsung (indirect effect) menggunakan metode Sobel ditunjukkan pada Tabel 11 berikut.

Tabel 11.

Hasil Pengujian Indirect Effect

\begin{tabular}{lcc}
\hline \hline \multicolumn{1}{c}{ Model Dugaan } & Standard Error & $Z_{\text {hitung }}$ \\
\hline Hipotesis A & 0,03069 & 1,631 \\
\hline Hipotesis B & 0,06709 & $2,268^{*}$ \\
\hline \hline
\end{tabular}

* Signifikan pada taraf signifikan 0,05

Tabel 11 menunjukkan hasil perhitungan nilai $Z$ yang akan dibandingan dengan nilai $Z_{(1-\alpha / 2)}$. Dengan menggunakan taraf signifikan sebesar 0,05 dan daerah penolakan $\mathrm{H}_{0}$ ditolak jika $Z_{\text {hitung }}>Z_{(0,025)}=1,96$ maka diperoleh kesimpulan terdapat pengaruh tidak langsung dari dukungan sosial terhadap kinerja karyawan melalui motivasi. Besarnya pengaruh tak langsung tersebut sebesar 0,622 × 0,556= 0,346 .

Model yang terbentuk dari analisis model struktural baik direct effect maupun indirect effect adalah sebagai berikut.

1. Motivasi $=0,622$ Dukungan Sosial

2. Kinerja $=0,556$ Motivasi $+0,622$ Dukungan Sosial

3. Kinerja $=0,598$ Kemampuan Diri

Interpretasi dari masing-masing persamaan model struktural yang signifikan adalah sebagai berikut.

1. Dukungan sosial berpengaruh signifikan sebesar 0,622 terhadap motivasi, artinya semakin tinggi dukungan yang diberikan oleh rekan kerja dan pengawas kepada karyawan maka motivasi karyawan dalam bekerja akan meningkat.

2. Motivasi berpengaruh signifikan sebesar 0,556 terhadap keterlibatan pekerjaan, artinya semakin tinggi motivasi karyawan maka kinerjanya akan semakin meningkat dan dukungan sosial berpengaruh signifikan sebesar 0,622 terhadap kinerja karyawan melalui motivasi, artinya semakin tinggi dukungan yang diterima oleh karyawan maka kinerjanya akan semakin meningkat.

3. Kemampuan diri berpengaruh signifikan sebesar 0,598 terhadap kinerja, artinya semakin tinggi kemampuan karyawan maka kinerjanya akan semakin meningkat.

Perbedaan model yang terbentuk dari direct effect maupun indirect effect yaitu pada variabel kinerja. Kinerja karyawan terdapat pengaruh langsung dari motivasi sebesar 0,556 dan pengaruh tidak langsung dari dukungan sosial sebesar 0,622. Kedua variabel tersebut jika digabungkan memberikan pengaruh terhadap kinerja karyawan sebesar 0,346 . Hal ini menunjukkan meskipun terdapat pengaruh tidak langsung dari dukungan sosial terhadap kinerja karyawan melalui motivasi namun pengaruhnya masih cenderung kecil dibandingkan dengan pengaruh secara langsung dari variabel motivasi terhadap kinerja karyawan.

\section{KESIMPULAN DAN SARAN}

\section{A. Kesimpulan}

Berdasarkan hasil analisis dan pembahasan diperoleh kesimpulan bahwa kemampuan diri dan motivasi berpengaruh signifikan secara langsung terhadap kinerja karyawan PT Djarum Unit Karangbener, Kudus-Jawa Tengah bagian proses giling artinya semakin tinggi motivasi dan kemampuan karyawan maka kinerjanya akan semakin meningkat, serta terdapat pengaruh signifikan secara langsung dari dukungan sosial terhadap motivasi artinya semakin tinggi dukungan yang diberikan oleh rekan kerja dan pengawas kepada karyawan maka motivasi karyawan dalam bekerja akan meningkat. Selain itu, dukungan sosial tidak berpengaruh secara langsung namun terdapat pengaruh tidak langsung dari dukungan sosial terhadap kinerja karyawan melalui motivasi.

\section{B. Saran}

Saran yang dapat diberikan peneliti untuk PT Djarum Unit Karangbener, Kudus adalah sebagai berikut.

1. Perusahaan perlu melakukan pemantauan terhadap kemampuan karyawan yang meliputi jadwal, tenaga, dan team work agar diketahui kelebihan dan kekurangan masing-masing karyawan sehingga karyawan akan selalu fokus dalam bekerja.

2. Perusahaan sebaiknya memberikan reward kepada karyawan sehingga memotivasi mereka untuk melakukan yang terbaik dalam bekerja.

3. Pengawas bagian produksi di proses giling diharapkan memberikan pengetahuan dan arahan kepada karyawan untuk dapat saling peduli dengan karyawan yang lain, tidak hanya rekan satu tim namun dengan rekan lainnya agar tercipta lingkungan kerja yang harmonis.

4. Penelitian selanjutnya sebaiknya menambah indikatorindikator penelitian dan menambah sampel penelitian agar diperoleh model yang lebih baik dan sesuai.

\section{DAFTAR PUSTAKA}

[1] M. Hariandja, Manajemen Sumber Daya Manusia. Jakarta: Grasindo, 2002.

[2] R. Mathis and J. Jackson, Manajemen Sumber Daya Manusia. Jakarta: Salemba Empat, 2001

[3] Muslimin, "Pengaruh Disiplin, Keterampilan, Kompensasi dan Masa Kerja Terhadap Kinerja Karyawan Administration and General Service pada PT Djarum Primary Kudus," Universitas Sunan Muria, 2013.

[4] I. Fauzi, "Pengaruh Kepemimpinan dan Motivasi Terhadap Kinerja Karyawan pada Unit SKT Brak BL 53 PT Djarum Kudus," Kudus, 2011.

[5] A. Wisaksono, "Analisis Keterlibatan Kerja dan Dukungan Organisasi Terhadap Kinerja dengan Mediasi Komitmen Organisasional (Studi Pada Dosen Polines)No Title," Semarang, 2014.

[6] I. Ghozali and I. Fuad, "Structural Equation Modeling: Teori, Konsep, dan Aplikasi dengan Program LISREL 8.54 (1st Edition)," Semarang, 2005.

[7] J. F. Hair, E. Rolph, L. Ronald, and C. B. William, Multivariate Data Analysis, 5th ed. New Jersey: Pearson Prentice Hall, 1998.

[8] S. Sharma, Applied Multivariate Techniques. Canada: John Wiley \& Sons Inc, 1996.

[9] R. A. Johnson and D. W. Wichern, Applied Multivariate Statistical Analysis. New Jersey: Prentice Hall, 2007.

[10] K. Bollen., Structural Equation With Laten Variables. USA: John Wiley \& Sons Inc, 1989. 
[11] H. Riniwati, Mendongkrak Motivasi dan Kinerja: Pendekatan Pemberdayaan SDM. Malang: UB Press, 2011.

[12] B. Arfida, Ekonomi Sumber Daya Manusia. Jakarta: PT Ghalia Indonesia, 2003

[13] S. P. Hasibuan, "Manajemen Sumber Daya Manusia,” 2007.

[14] E. Sarafino, Health Psychology Biopsychological Interaction.
New Jersey: John Wiley \& Sons, Inc, 2002.

[15] M. Blum and I. . Naylor, Industrial Psychology, Theoritical and Social Foundation. New York: Harper And Row Publisher, 1986.

[16] I. Hendrik, "Unsur Kreativitas dalam Supervisi Pengajaran dan Pengembangan Situasi Belajar Mengajar,” Bandung, 1989. 